\title{
Allosteric Activation Shifts the Rate-Limiting Step in a Short-Form ATP Phosphoribosyltransferase
}

\author{
Gemma Fisher, ${ }^{\ddagger}$ Catherine M. Thomson, ${ }^{\ddagger}$ Rozanne Stroek, ${ }^{\ddagger}$ Clarissa M. Czekster, ${ }^{\ddagger}$ Jennifer S. Hirschi, ${ }^{*}, \S$ \\ and Rafael G. da Silva*, ${ }^{*}+0$ \\ ${ }^{\ddagger}$ School of Biology, Biomedical Sciences Research Complex, University of St Andrews, St Andrews, Fife KY16 9ST, United Kingdom \\ ${ }^{\S}$ Department of Chemistry, Binghamton University, Binghamton, New York 13902, United States
}

\section{Supporting Information}

ABSTRACT: Short-form ATP phosphoribosyltransferase (ATPPRT) is a hetero-octameric allosteric enzyme comprising four catalytic subunits $\left(\mathrm{His}_{\mathrm{S}}\right.$ ) and four regulatory subunits (HisZ). ATPPRT catalyzes the $\mathrm{Mg}^{2+}$-dependent condensation of ATP and 5-phospho- $\alpha$-D-ribosyl-1-pyrophosphate (PRPP) to generate $N^{1}$-(5-phospho- $\beta$-D-ribosyl)-ATP (PRATP) and pyrophosphate, the first reaction of histidine biosynthesis. While His $\mathrm{G}_{\mathrm{S}}$ is catalytically active on its own, its activity is allosterically enhanced by HisZ in the absence of histidine. In the presence of

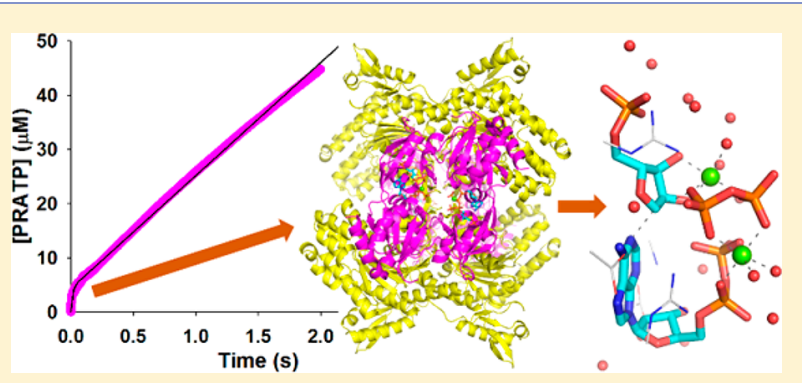
histidine, HisZ mediates allosteric inhibition of ATPPRT. Here, initial velocity patterns, isothermal titration calorimetry, and differential scanning fluorimetry establish a distinct kinetic mechanism for ATPPRT where PRPP is the first substrate to bind. AMP is an inhibitor of HisG $_{S}$, but steady-state kinetics and ${ }^{31} \mathrm{P}$ NMR spectroscopy demonstrate that ADP is an alternative substrate. Replacement of $\mathrm{Mg}^{2+}$ by $\mathrm{Mn}^{2+}$ enhances catalysis by $\mathrm{His}_{\mathrm{S}}$ but not by the holoenzyme, suggesting different rate-limiting steps for nonactivated and activated enzyme forms. Density functional theory calculations posit an $\mathrm{S}_{\mathrm{N}} 2$-like transition state stabilized by two equivalents of the metal ion. Natural bond orbital charge analysis points to $\mathrm{Mn}^{2+}$ increasing $\mathrm{HisG}_{\mathrm{S}}$ reaction rate via more efficient charge stabilization at the transition state. High solvent viscosity increases $\mathrm{HisG}_{\mathrm{S}}$ 's catalytic rate, but decreases the hetero-octamer's, indicating that chemistry and product release are rate-limiting for $\mathrm{HisG}_{\mathrm{S}}$ and ATPPRT, respectively. This is confirmed by pre-steady-state kinetics, with a burst in product formation observed with the hetero-octamer but not with $\mathrm{His}_{\mathrm{S}}$. These results are consistent with an activation mechanism whereby HisZ binding leads to a more active conformation of $\mathrm{His}_{\mathrm{S}}$, accelerating chemistry beyond the product release rate.

A llosteric control of catalysis is a widespread strategy evolved in biosynthetic pathways. ${ }^{1-4}$ The modulation of biochemical pathways for synthetic biology applications often requires overcoming or manipulating allosteric regulation., Furthermore, allosteric sites provide a more selective avenue for drug design in comparison with active sites, which tend to be more conserved. ${ }^{3,7,8}$ Accordingly, the elucidation of allosteric mechanisms in multiprotein enzymatic complexes paves the way for future therapeutic and biotechnological applications.

The allosteric enzyme adenosine 5 '-triphosphate phosphoribosyltransferase (ATPPRT) (EC 2.4.2.17), responsible for the first and flux-controlling step in histidine biosynthesis, ${ }^{9}$ is a potential drug target in some pathogenic organisms, ${ }^{8,10-12}$ the focus of synthetic biology endeavors to harness the histidine biosynthetic pathway for histidine production in bacteria, ${ }^{6,13,14}$ and a model system for the study of allosteric regulation of catalysis. $^{3,8,15,16}$

ATPPRT catalyzes the $\mathrm{Mg}^{2+}$-dependent and reversible nucleophilic substitution of adenosine 5 -triphosphate (ATP) $\mathrm{N} 1$ on 5-phospho- $\alpha$-D-ribosyl-1-pyrophosphate (PRPP) C1 to generate $N^{1}$-(5-phospho- $\beta$-D-ribosyl)-ATP (PRATP) and inorganic pyrophosphate $\left(\mathrm{PP}_{\mathrm{i}}\right)$ (Scheme 1$),{ }^{9}$ with the chemical equilibrium highly displaced toward reactants. ${ }^{17}$ The metabolic status of the cell regulates ATPPRT activity via allosteric inhibition by histidine $e^{9,18}$ and orthosteric inhibition by

Scheme 1. ATPPRT-Catalyzed Nucleophilic Substitution Reaction

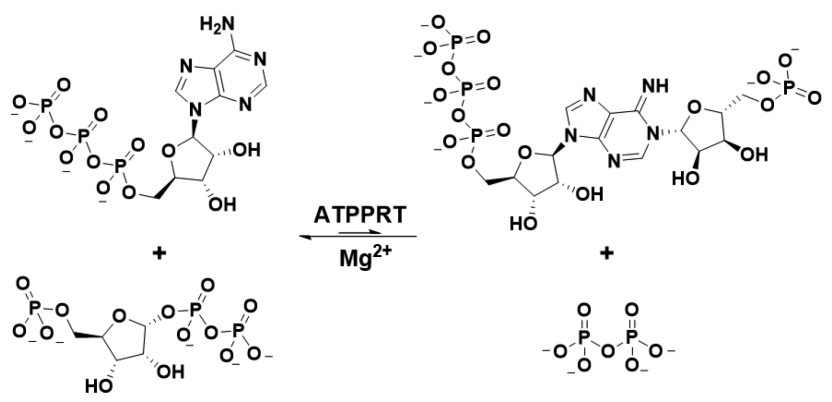

Received: May 17, 2018

Revised: June 15, 2018

Published: June 25, 2018 
adenosine $5^{\prime}$-monophosphate (AMP). ${ }^{19}$ Intriguingly, orthosteric inhibition by adenosine $5^{\prime}$-diphosphate (ADP) is also reported. $^{19}$

The hisG gene encodes two forms of ATPPRT. Most histidine-synthesizing organisms possess a long-form of the protein, $\mathrm{HisG}_{\mathrm{L}},{ }^{16,28}$ a homohexamer with each subunit consisting of two N-terminal catalytic domains and a $\mathrm{C}$ terminal allosteric domain responsible for histidine inhibition. ${ }^{11}$ HisG $_{\mathrm{L}}$ ATPPRTs operate by a steady-state ordered kinetic mechanism where ATP is the first substrate to bind to, and PRATP the last product to dissociate from, the enzyme. $^{21,22}$

Archaea and some eubacteria have instead a short-form of the protein, $\mathrm{HisG}_{\mathrm{S}}{ }^{23,24}$ a homodimer with each subunit comprising two catalytic domains homologous to $\mathrm{HisG}_{\mathrm{L}}$ 's, but lacking the C-terminal allosteric domain. ${ }^{20,25}$ Thus, $\mathrm{HisG}_{\mathrm{S}}$ is catalytically active on its own but insensitive to inhibition by histidine. ${ }^{20,26} \mathrm{HisG}_{\mathrm{S}}$ binds HisZ, the product of the hisZ gene, a catalytically inactive paralogue of histidyl-tRNA synthetase, ${ }^{23}$ forming the hetero-octameric ATPPRT holoenzyme, where two $\mathrm{HisG}_{\mathrm{S}}$ dimers flank a HisZ tetramer. ${ }^{24,26,27} \mathrm{HisZ}$ has two distinct allosteric functions: in the absence of histidine, it activates catalysis by $\mathrm{HisG}_{S}$, and in the presence of histidine, it binds the final product of the pathway and mediates allosteric inhibition of $\mathrm{HisG}_{\mathrm{S}}{ }^{20,24,26,28}$ The kinetic mechanism of HisG ATPPRTs has not been investigated, but recent crystal structures suggest that the order of substrate binding may be different from $\mathrm{HisG}_{\mathrm{L}}$ 's. ${ }^{29}$ Moreover, little is known about the kinetics of allosteric activation.

We recently reported several crystal structures of the psychrophilic bacterium Psychrobacter arcticus dimeric $\mathrm{HisG}_{\mathrm{S}}$ $\left(\mathrm{PaHis} \mathrm{G}_{\mathrm{S}}\right)$ and hetero-octameric ATPPRT holoenzyme (PaATPPRT), ${ }^{26,29}$ from which an activation mechanism was inferred that involves tightening of the $\mathrm{PaHisG}_{\mathrm{S}}$ dimer in the hetero-octamer when both substrates are bound (Figure 1), which facilitates leaving group stabilization at the transition state. ${ }^{29}$ Here we employ initial rate studies, isothermal titration calorimetry (ITC), differential scanning fluorimetry (DSF), ${ }^{31} \mathrm{P}$ nuclear magnetic resonance $\left({ }^{31} \mathrm{P} \mathrm{NMR}\right)$, liquid chromatog-

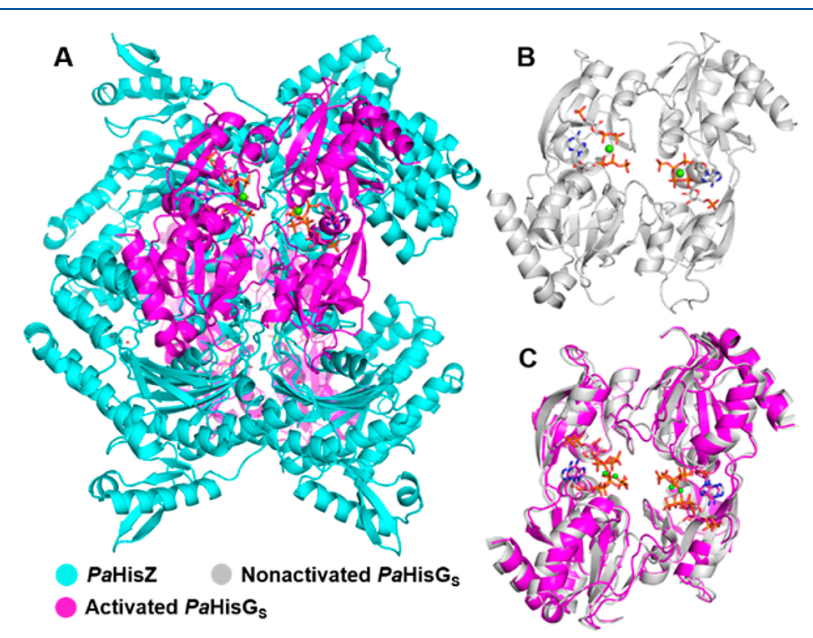

Figure 1. $P a H_{i s} G_{S}$ and $P a A T P P R T$ quaternary structures and allosteric activation. (A) PaATPPRT hetero-octamer, where catalysis is enhanced. The second $\mathrm{PaHisG}$ homodimer is behind the $\mathrm{PaHisZ}$ tetramer. (B) Nonactivated $\mathrm{PaHisG}_{\mathrm{S}}$ homodimer and (C) overlay of activated and nonactivated $\mathrm{PaHis} \mathrm{G}_{\mathrm{S}}$ dimers. In all structures, $\mathrm{PaHis} \mathrm{G}_{\mathrm{S}}$ is bound to PRPP, ATP, and $\mathrm{Mg}^{2+}$. raphy-mass spectrometry (LC-MS), density functional theory, solvent viscosity effects, and pre-steady-state kinetics to unveil a distinct kinetic mechanism for PaATPPRT, the role of ADP as a substrate instead of an inhibitor, the basis for chargestabilization at the transition state, and a shift in the rate-liming step upon allosteric activation of the enzyme.

\section{MATERIALS AND METHODS}

Materials. ATP, PRPP, $\mathrm{PP}_{\mathrm{i}}, \mathrm{AMP}, \mathrm{ADP}, \mathrm{MgCl}_{2}, \mathrm{MnCl}_{2}$, $\mathrm{D}_{2} \mathrm{O}$ (99.9 atom \% deuterium), tricine, dithiothreitol (DTT), and glycerol were purchased from Sigma-Aldrich. All other chemicals were purchased from readily available commercial sources, and all chemicals were used without further purification. PaHisG, $\mathrm{PaHisZ}$, Mycobacterium tuberculosis pyrophosphatase (MtPPase), and tobacco etch virus protease were obtained as previously published. ${ }^{26}$ PRATP was produced as previously described. ${ }^{29}$

PaHisG $_{\mathrm{s}}$ and PaATPPRT Activity Assay. All assays were performed under initial rate conditions in the forward direction at $20^{\circ} \mathrm{C}$ as previously described ${ }^{26}$ by monitoring the increase in absorbance at $290 \mathrm{~nm}$ due to formation of PRATP $\left(\varepsilon_{290 \mathrm{~nm}}\right.$ $\left.=3600 \mathrm{M}^{-1} \mathrm{~cm}^{-1}\right)^{30}$ in $1 \mathrm{~cm}$ path length quartz cuvettes (Hellma) in a Shimadzu UV-2600 spectrophotometer. Unless stated otherwise, for $\mathrm{PaHis} \mathrm{H}_{\mathrm{S}}$ activity, $\mathrm{PaHisG}$. concentration was $2.2 \mu \mathrm{M}$, and for PaATPPRT activity, $\mathrm{PaHisG}_{\mathrm{S}}$ and PaHisZ concentrations were 0.38 and $15 \mu \mathrm{M}$, respectively. Reactions were started by addition of PRPP. Control reactions lacked either ATP, PRPP, $\mathrm{PaHisG}_{\mathrm{S}}$, or $\mathrm{PaHisZ}$. In all kinetic experiments under the various different conditions described below, controls were carried out to ensure that the rate did not depend on MtPPase. Kinetic measurements were performed at least in duplicates unless stated otherwise.

PaATPPRT Equilibrium Dissociation Constant $\left(K_{\mathrm{D}}\right)$ in Glycerol. Initial velocities were measured in the presence of $5.6 \mathrm{mM}$ ATP, $2 \mathrm{mM}$ PRPP, $0.38 \mu \mathrm{M} \mathrm{PaHisG}$, and varying concentrations of $\mathrm{PaHisZ}(0.9-8.5 \mu \mathrm{M})$ in $0 \%,(0.5-16.3$ $\mu \mathrm{M})$ in $18 \%$ and $27 \%$ glycerol (v/v). PaHisZ-PaHisG $K_{\mathrm{S}}$ values were obtained by fitting initial rate data to a kinetic equation (vide infra) as previously reported. ${ }^{26}$

PaATPPRT and PaHisG s Saturation Kinetics with ATP and PRPP. PaATPPRT initial rates were measured at saturating concentrations of one substrate and varying concentrations of the other, either ATP $(0.4-5.6 \mathrm{mM})$ or PRPP $(0.1-2.0 \mathrm{mM})$. Initial rates for $\mathrm{PaHisG}_{\mathrm{S}}$ were determined at saturating concentrations of one substrate and varying concentrations of the other, either ATP (either 0.42.8 or $0.4-5.6 \mathrm{mM})$ or PRPP $(0.1-2.0 \mathrm{mM})$.

PaATPPRT and PaHisG $_{\mathrm{S}}$ Saturation Kinetics with $\mathrm{MnCl}_{2}$. PaATPPRT initial rates were measured at saturating concentrations of one substrate and varying concentrations of the other, either ATP $(0.1-1.4 \mathrm{mM})$ or PRPP $(0.1-2.0 \mathrm{mM})$, while initial rates for $\mathrm{PaHisG}_{\mathrm{S}}(1.1 \mu \mathrm{M})$ were determined at saturating concentrations of one substrate and varying concentrations of the other, either ATP $(0.1-1.4 \mathrm{mM})$ or PRPP (0.05-2.0 mM), in the presence of $15 \mathrm{mM} \mathrm{MnCl}_{2}$ instead of $\mathrm{MgCl}_{2}$.

Analysis of $\mathrm{PaHisG}_{\mathrm{s}}$ Reaction with $\mathrm{MnCl}_{2}$ by LC-MS. Reaction mixtures $(500 \mu \mathrm{L})$ contained $100 \mathrm{mM}$ tricine $\mathrm{pH} 8.5$, $100 \mathrm{mM} \mathrm{KCl}, 4 \mathrm{mM}$ DTT, $15 \mathrm{mM} \mathrm{MnCl}_{2}, 19.7 \mu \mathrm{M}$ MtPPase, 1.4 mM ATP, 2.0 mM PRPP, and 10.3 $\mu \mathrm{M} \mathrm{PaHisG}$. Reactions were incubated for $1 \mathrm{~h}$ at $20{ }^{\circ} \mathrm{C}$, after which proteins were removed by passage through 10000 MWCO Vivaspin centrifugal concentrators. Reactions were run in duplicate, 
and control reactions lacked $\mathrm{PaHisG}_{\mathrm{S}}$. LC-MS analysis of the protein-free reaction mixtures was performed on an EC250/4.6 Nucleodur 100-10 C18 ec HPLC column $(10 \mu \mathrm{m} \times 4.6 \mathrm{~mm}$ $\times 250 \mathrm{~mm}$ ) (Macherey-Nagel) in a 1260 infinity HPLC system coupled to a G6130B Single Quadrupole mass spectrometer (Agilent Technologies). Separation of PRATP and ATP was carried out in (A) $50 \mathrm{mM}$ triethylamine-acetic acid $\mathrm{pH} 7.4$ and (B) methanol as a mobile phase in the following sequence: 03 min $100 \%$ A, 3-3.1 min $90 \%$ A and $10 \%$ B, 3.1-12 min $80 \%$ A and $20 \% \mathrm{~B}$ at a flow rate of $1 \mathrm{~mL} \mathrm{~min}^{-1}$, with UV absorbance monitored at 260 and $290 \mathrm{~nm}$. Electrospray ionization-mass spectrometry (ESI-MS) data were acquired in negative mode with a capillary voltage of $4500 \mathrm{~V}$.

PaATPPRT and PaHisG $_{s}$ Saturation Kinetics in Glycerol. $\mathrm{PaATPPRT}$ and $\mathrm{PaHisG}_{\mathrm{S}}$ initial rates were measured at saturating concentrations of one substrate and varying concentrations of the other, either ATP $(0.4-5.6 \mathrm{mM})$ or PRPP $(0.1-2.0 \mathrm{mM})$, in the presence of $0 \%, 18 \%$, and $27 \%$ glycerol $(\mathrm{v} / \mathrm{v})$.

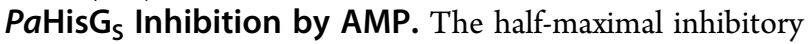
concentration of AMP was determined by measuring initial rates for $\mathrm{PaHisG}_{\mathrm{S}}(4.5 \mu \mathrm{M})$ in the presence of $5.6 \mathrm{mM}$ ATP, 2 $\mathrm{mM}$ PRPP, and varying concentrations of AMP $(0-0.8 \mathrm{mM})$. The inhibition mechanism was investigated by measuring initial rates for $\mathrm{PaHisG}_{\mathrm{S}}(4.5 \mu \mathrm{M})$ at saturating concentrations of one substrate and varying concentrations of the other, either ATP (0.4-5.6 mM) with different concentrations of AMP (0$0.1 \mathrm{mM})$ or PRPP $(0.1-2.0 \mathrm{mM})$ with different concentrations of AMP (0-0.05 mM). $\mathrm{PaHis} \mathrm{S}_{\mathrm{S}}$ concentration was more than 4-fold higher than the lowest AMP concentration used, and pseudo-first-order approximation was assumed.

$\mathrm{PaHisG}_{\mathrm{S}}$ Saturation Kinetics with ADP and PRPP. Initial rates for $\mathrm{PaHis}_{\mathrm{S}}$ were determined at saturating concentrations of one substrate and varying concentrations of the other, either $\mathrm{ADP}(0.4-5.6 \mathrm{mM})$ or PRPP (0.1-2.0 $\mathrm{mM})$.

Comparison of $\mathrm{PaHisG}_{\mathrm{S}}$ Reactions with ADP and ATP by ${ }^{31} \mathrm{P}$ NMR Spectroscopy. Analysis of $\mathrm{PaHisG}_{\mathrm{S}}$ reactions by ${ }^{31} \mathrm{P}$ NMR spectroscopy was carried out as previously described, ${ }^{26}$ except that $\mathrm{PaHisG}_{\mathrm{S}}$ concentration was $10.3 \mu \mathrm{M}$ and ADP replaced ATP in half of the reactions. All reactions were run in duplicate, and control reactions lacked $P a H_{i s} G_{S}$.

PaATPPRT and PaHisG $_{\mathrm{s}}$ Initial Velocity Patterns. Initial rates for $P a A T P P R T$ were measured in the presence of varying ATP (0.4-5.6 mM) and PRPP (0.1-2.0 mM), with $1 \mu \mathrm{M}$

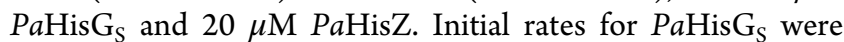
determined in the presence of varying ATP $(0.2-2.8 \mathrm{mM})$ and PRPP (0.1-2.0 $\mathrm{mM})$. Measurements were performed in quadruplicates.

PaHisG $_{\mathrm{S}}$ Binding by ITC. ITC measurements were carried out at $20{ }^{\circ} \mathrm{C}$ in a MicroCal PEAQ-ITC calorimeter (Malvern Instruments). Protein and ligand were solubilized in the same ATPPRT assay buffer. After a small injection of $0.4 \mu \mathrm{L}, 18$ successive injections of $2 \mu \mathrm{L}$ of ligand (either $0.8 \mathrm{mM}$ PRPP or $10 \mathrm{mM}$ ATP) were made into $300 \mu \mathrm{L}$ of $50 \mu \mathrm{M} \mathrm{PaHisG}$, with 150 -s intervals between successive injections and a reference power of $10 \mu \mathrm{cal} \mathrm{s}^{-1}$. Heat of dilution for each experiment was measured by titrating ligand into assay buffer, and subtracted from the corresponding binding curve. All measurements were performed in duplicate. Data for PRPP binding were fitted to a single-site binding model as implemented in the PEAQ-ITC analysis software (Malvern Instruments).
PaHisG $_{\mathrm{S}}$ Thermal Denaturation by DSF. DSF measurements $\left(\lambda_{\mathrm{ex}}=490 \mathrm{~nm}, \lambda_{\mathrm{em}} 610 \mathrm{~nm}\right)$ were performed in 96-well plates on a Stratagene Mx3005p instrument. Thermal denaturation assays $(50 \mu \mathrm{L})$ for $7.5 \mu \mathrm{M} \quad \mathrm{PaHisG}_{\mathrm{S}}$ were measured in the presence and absence of ligands (6 mM ATP, $2 \mathrm{mM}$ PRPP, $208 \mu \mathrm{M}$ PRATP, $3.6 \mathrm{mM} \mathrm{PP}_{\mathrm{i}}$ ), with or without $22 \%$ glycerol (v/v) (apoenzyme) in $100 \mathrm{mM}$ tricine, $100 \mathrm{mM}$ $\mathrm{KCl}, 4 \mathrm{mM} \mathrm{DTT}$ and $15 \mathrm{mM} \mathrm{MgCl} 2 \mathrm{pH}$ 8.5. The assay for apoenzyme was also performed in $10 \mathrm{mM} \mathrm{KH} \mathrm{PO}_{4}, 10 \mathrm{mM}$ $\mathrm{KF} \mathrm{pH}$ 8.0. Sypro Orange ( $5 \times$ ) (Invitrogen) was added to all wells. Thermal denaturation curves were recorded over a temperature range from $25-93{ }^{\circ} \mathrm{C}$ with $1{ }^{\circ} \mathrm{C} \mathrm{min}^{-1}$ increments. Control curves lacked enzyme and were subtracted from curves containing enzyme. All measurements were carried out in triplicate.

Density Functional Theory Calculations. Theoretical structures were derived from B3LYP calculations using a 6$31 \mathrm{G}^{*}$ basis set with a Lanl2DZ basis set on $\mathrm{Mg}^{2+}$ and $\mathrm{Mn}^{2+}$ and a Lanl2DZ pseudopotential added to $\mathrm{Mg}^{2+}$ and $\mathrm{Mn}^{2+}$ as implemented in Gaussian 09. ${ }^{31}$ A model system was chosen by including all residues within $5 \AA$ of ADP and PRPP in the crystallographic dimer of the $\mathrm{PaHisG}_{\mathrm{S}}$-PRPP-Mg-ADP complex crystal structure ${ }^{29}$ and by flipping the adenine ring from its crystal structure orientation to bring $\mathrm{N} 1$ in proximity to PRPP. The system was further paired down to include only functional groups, metal ions and water molecules within the 5 - $\AA$ cutoff that were essential for stabilization of the transition structure. In addition to the divalent metal found in the crystal structure, a second divalent metal had to be included in the system for a transition structure to be located. Initial searches exploring structures with fixed distances along the reaction coordinate were located by performing an optimization of an input structure with the key bond-forming or bond-breaking distances held constant, and frequency calculations resulted in only one imaginary frequency along the reaction coordinate. Final transition structures for the system complexed with either $\mathrm{Mg}^{2+}$ or $\mathrm{Mn}^{2+}$ were located as stationary points with no geometrical constrains and exhibit only one imaginary frequency along the reaction coordinate. Coordinates for all optimized structures are available in the Supporting Information.

Pre-Steady-State Kinetics. Approach to steady-state in $\mathrm{PaHisG}_{\mathrm{S}}$ and $\mathrm{PaATPPRT}$ reactions was investigated under multiple-turnover conditions by monitoring the increase in absorbance at $290 \mathrm{~nm}$ upon PRATP formation at $20^{\circ} \mathrm{C}$ in an Applied Photophysics SX-20 stopped-flow spectrophotometer outfitted with a $5 \mu \mathrm{L}$ mixing cell $(0.5 \mathrm{~cm}$ path length and 0.9 $\mathrm{ms}$ dead-time). Each syringe contained $100 \mathrm{mM}$ tricine $\mathrm{pH} 8.5$, $100 \mathrm{mM} \mathrm{KCl}, 4 \mathrm{mM} \mathrm{DTT}, 15 \mathrm{mM} \mathrm{MgCl}_{2}$, and $20 \mu \mathrm{M}$

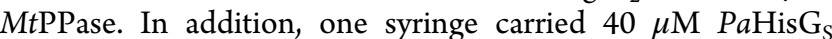
(with or without $100 \mu \mathrm{M} \mathrm{PaHisZ)} \mathrm{and} 4 \mathrm{mM}$ PRPP, while the other carried $11.2 \mathrm{mM}$ ATP. Reaction was triggered by rapidly mixing $55 \mu \mathrm{L}$ from each syringe. Absorbance increase with $\mathrm{PaHis}_{\mathrm{S}}$ was monitored in a linear-time base for $5 \mathrm{~s}$ with 5000 data points collected, and with $\mathrm{PaATPPRT}$, in a split-time base for $2 \mathrm{~s}$, with 4000 data points collected in the first $0.2 \mathrm{~s}$ and 4000 in the following $1.8 \mathrm{~s}$. At least 8 traces were acquired for each enzyme, and controls lacked PRPP.

Data Analysis of Kinetics and Thermal Denaturation. Kinetic and DSF data were analyzed by the nonlinear regression function of SigmaPlot 13 (SPSS Inc.). Data points and error bars in graphs are represented as mean \pm standard error, and kinetic and equilibrium constants are presented as 
mean \pm fitting error. Initial rate data with varying concentrations of $\mathrm{PaHisZ}$ were fitted to eq 1 . The concentration of $\mathrm{PaATPPRT}$ at any concentration of $\mathrm{PaHisG}_{\mathrm{S}}$ and $\mathrm{PaHisZ}$ was calculated according to eq 2 . Substrate saturation data were fitted to eq 3 . Inhibition data at fixed substrate concentrations were fitted to eq 4 , and competitive inhibition data were fitted to eq 5 . Initial velocity patterns were fitted to eq 6, and pre-steady-state kinetics under multipleturnover conditions was fitted to eq 7 . In eqs $1-7, v$ is the initial rate, $V_{\max }$ is the maximal velocity, $G$ is the concentration of $\mathrm{PaHisG}_{\mathrm{S}}, \mathrm{Z}$ is the concentration of $\mathrm{PaHisZ}, K_{\mathrm{D}}$ is the equilibrium dissociation constant, $P a A T P P R T$ is the concentration of $\mathrm{PaHis}_{\mathrm{S}} \mathrm{PaHisZ}$ complex, $\mathrm{S}$ is the concentration of the varying substrate, $k_{\text {cat }}$ is the steady-state turnover number, $K_{\mathrm{M}}$ is the apparent Michaelis constant, $E_{\mathrm{T}}$ is total enzyme concentration, $v_{\mathrm{i}}$ is the initial rate in the presence of inhibitor, $\mathrm{IC}_{50}$ is the half-maximal inhibitory concentration, $K_{\mathrm{i}}$ is the inhibitor dissociation constant, $A$ and $B$ are the first and second substrates to bind to the enzyme, respectively, $K_{\mathrm{a}}$ and $K_{\mathrm{b}}$ are their respective Michaelis constants, $K_{\mathrm{ia}}$ is the apparent dissociation constant for the complex between enzyme and substrate $A$ when the concentration of $B$ approaches zero, $t$ is time, $P(t)$ is product concentration at time $t, A_{0}$ is the amplitude of the burst phase, and $k_{\text {burst }}$ is the first-order rate constant of product formation in the burst phase. DSF thermal denaturation data were fitted to eq $8,{ }^{32}$ where $F_{\mathrm{U}}$ is fraction unfolded, $T$ is the temperature in ${ }^{\circ} \mathrm{C}, T_{\mathrm{m}}$ is the melting temperature, $c$ is the slope of the transition region, and $L L$ and $U L$ are folded and unfolded baselines, respectively.

$$
v=V_{\max } \frac{\left(G+Z+K_{\mathrm{D}}\right)-\sqrt{\left(G+Z+K_{\mathrm{D}}\right)^{2}-4 G Z}}{2 G}
$$

\section{PaATPPRT}

$$
=\frac{\left(G+Z+K_{\mathrm{D}}\right)-\sqrt{\left(G+Z+K_{\mathrm{D}}\right)^{2}-4 G Z}}{2}
$$

$$
\begin{aligned}
& \frac{v}{E_{\mathrm{T}}}=\frac{k_{\mathrm{cat}} S}{K_{\mathrm{M}}+S} \\
& \frac{v_{\mathrm{i}}}{v}=\frac{1}{1+\frac{I}{\mathrm{IC}_{\mathrm{s} 0}}} \\
& \frac{v}{E_{\mathrm{T}}}=\frac{k_{\mathrm{cat}} S}{\left(1+{ }^{I} / K_{\mathrm{i}}\right) K_{\mathrm{M}}+S} \\
& \frac{v}{E_{\mathrm{T}}}=\frac{k_{\mathrm{cat}} A B}{K_{\mathrm{ia}} K_{\mathrm{b}}+K_{\mathrm{a}} B+K_{\mathrm{b}} A+A B} \\
& P(t)=A_{0}\left(1-\mathrm{e}^{\left.-k_{\mathrm{burst}}{ }^{t}\right)+v t}\right. \\
& F_{\mathrm{U}}=L L+\frac{U L-L L}{1+\mathrm{e}^{\left(T_{\mathrm{m}}-T\right) / c}}
\end{aligned}
$$

\section{RESULTS AND DISCUSSION}

PaHisG $_{\mathrm{S}}$ and PaATPPRT Kinetic Mechanism. A steadystate ordered kinetic mechanism in which ATP is the first substrate to bind to the enzyme, and PRATP is the last product to dissociate from it, has long been demonstrated for HisG $_{\mathrm{L}}$ ATPPRTs. ${ }^{21,22}$ This mechanism has been supported by several structures of Campylobacter jejuni and M. tuberculosis ATPPRT-ATP binary complexes, ${ }^{10,16}$ and by the recent structure of the $C$. jejuni ATPPRT catalytic core in complex with PRPP, where despite being able to bind to the free enzyme, PRPP drifts into the ATP binding site, which would lead to a dead-end complex. ${ }^{33}$ The kinetic mechanism of $\mathrm{HisG}_{\mathrm{S}}$ ATPPRTs, on the other hand, has not been explored. We recently published the crystal structures of $\mathrm{PaHisG}_{\mathrm{S}}$ and PaATPPRT in binary complexes with PRPP and PRATP, and in ternary complexes with PRPP-ATP, but were unable to obtain structures of enzyme-ATP binary complexes, suggesting a reverse order of substrate binding in comparison with $\mathrm{HisG}_{\mathrm{L}}$ ATPPRTs. $^{29}$

To test this hypothesis, the kinetic mechanism of $\mathrm{PaHis}_{\mathrm{S}}$ and $\mathrm{PaATPPRT}$ was investigated. Intersecting patterns of double-reciprocal plots with both ATP and PRPP in initial velocity studies were determined for PaATPPRT (Figure 2A,B) and $\mathrm{PaHisG}_{\mathrm{S}}$ (Figure 2C,D), indicating a ternary

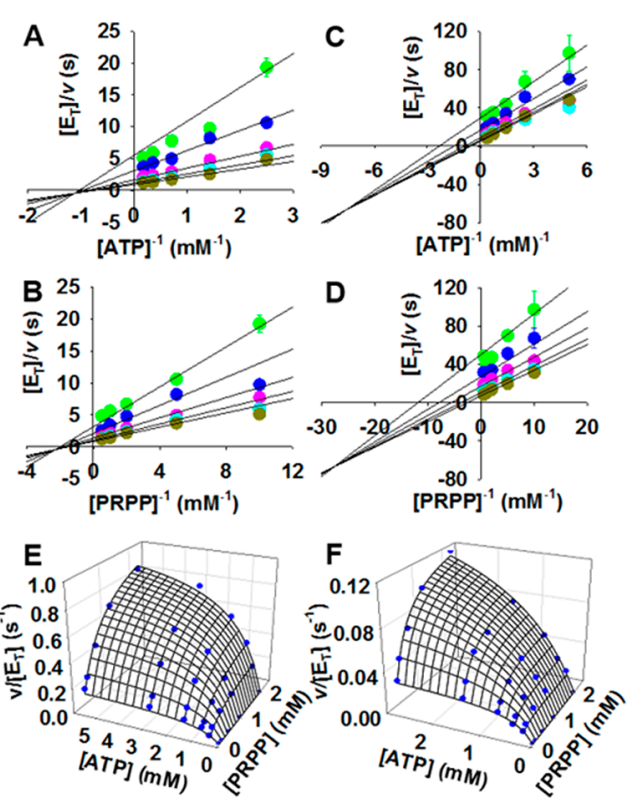

Figure 2. Initial velocity patterns for $\mathrm{PaATPPRT}$ and $\mathrm{PaHis} \mathrm{G}_{\mathrm{s}}$. Intersecting double-reciprocal plots for PaATPPRT with (A) ATP and (B) PRPP as varying substrates and for $\mathrm{PaHisG}_{\mathrm{S}}$ with (C) ATP and (D) PRPP as varying substrates. Each color represents a different fixed concentration of the cosubstrate. Data points are mean \pm SE. Three-dimensional plot of (E) PaATPPRT and (F) $\mathrm{PaHisG}_{\mathrm{S}}$ initial rate data, where lines are data fitting to eq 6 .

complex is formed in a sequential mechanism. The doublereciprocal plots intersecting to the left of the $y$-axes rule out a rapid equilibrium ordered mechanism. ${ }^{34}$ Fitting the data to eq 6 (Figure 2E,F) yielded steady-state kinetic parameters summarized in Table S1.

Binding studies were performed with $\mathrm{PaHisG}_{\mathrm{S}}$ to elucidate the substrate binding order. Binding of PRPP to $\mathrm{PaHis}_{\mathrm{S}}$ was detected by ITC (Figure S1), and fitting the data from two independent experiments to a single-site binding model (stoichiometry of $1: 1$ and no cooperativity) resulted in $K_{\mathrm{D}}$ 's of $15.4 \pm 0.2$ and $8.3 \pm 0.1 \mu \mathrm{M}$ (one from each experiment, yielding a mean \pm SE of $12 \pm 2 \mu \mathrm{M})$. ATP binding to $\mathrm{PaHisG}_{\mathrm{S}}$, on the other hand, could not be detected, as no signal was observed beyond heat of dilution (Figure S2). This 
corroborates the hypothesis that PRPP can bind to the free enzyme, while ATP cannot.

To confirm and expand these results, $\mathrm{PaHis}_{\mathrm{S}}$ thermal denaturation curves in the presence and absence of substrates and products were determined by DSF (Figure 3), and data

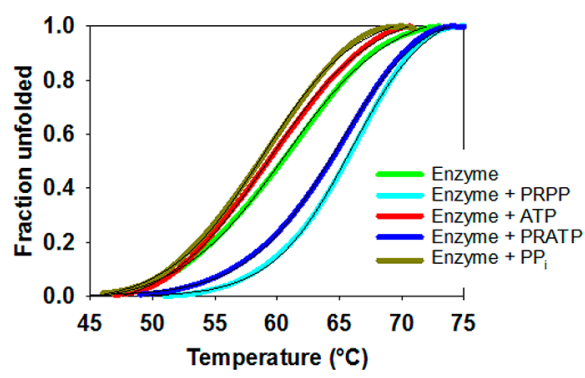

Figure 3. DSF-based thermal denaturation of $\mathrm{PaHisG}$ apoenzyme and in the presence of substrates and products. Thin black lines are data fitting to eq 8 .

fitting to eq 8 produced $T_{\mathrm{m}}$ 's shown in Table S2. PRPP and PRATP increased $\mathrm{PaHisG}_{\mathrm{S}} T_{\mathrm{m}}$ by 6 and $5{ }^{\circ} \mathrm{C}$, respectively, indicating that these molecules can bind to the free enzyme. Conversely, ATP and $\mathrm{PP}_{\mathrm{i}}$ did not alter $\mathrm{PaHisG}_{\mathrm{S}} T_{\mathrm{m}}$. The latter observation alone does not necessarily rule out the possibility that ATP and $\mathrm{PP}_{\mathrm{i}}$ can bind to the free enzyme, but the integration of crystallography, ${ }^{29}$ initial velocity patterns, ITC, and DSF data supports a steady-state ordered mechanism where PRPP is the first substrate to bind to $\mathrm{PaHisG}_{\mathrm{S}}$ and PRATP is the last product to dissociate from it. The strong parallels in corresponding binding modes seen in the $\mathrm{PaHis}_{\mathrm{S}}$ and PaATPPRT crystal structures ${ }^{29}$ suggest that PaATPPRT follows the same mechanism. Moreover, given the conservation of PRPP position in PaATPPRT ${ }^{29}$ and Lactococcus lactis ATPPRT binary complexes, ${ }^{27}$ this mechanism may be valid for other $\mathrm{HisG}_{\mathrm{S}}$ ATPPRTs.

AMP Is an Inhibitor of PaHisG $_{\mathrm{s}}$. AMP is a competitive inhibitor of $\mathrm{HisG}_{\mathrm{L}}$ ATPPRTs against both substrates, ${ }^{16,19}$ which is explained structurally by the simultaneous partial occupation of the PRPP and ATP binding sites by AMP's phosphoribosyl and adenine moieties, respectively. ${ }^{11,16,35}$ AMP is also a competitive inhibitor against PRPP in L. lactis ATPPRT, ${ }^{28}$ and the recent crystal structure of the $\mathrm{PaHisG}_{\mathrm{S}^{-}}$ AMP complex shows a similar binding mode as in $\mathrm{His}_{\mathrm{L}}$ ATPPRTs. ${ }^{11,16,29,35}$ AMP inhibits $\mathrm{PaHisG}_{\mathrm{S}}$ with an $\mathrm{IC}_{50}$ of 79 $\pm 6 \mu \mathrm{M}$ (Figure $\mathrm{S} 3 \mathrm{~A}$ ), and inhibition is competitive against both PRPP and ATP, with $K_{\mathrm{i}}^{\prime}$ s of $25 \pm 5$ and $52 \pm 8 \mu \mathrm{M}$, respectively (Figure S3B,C). These values are on average ca. 7and 10-fold lower than those for $\mathrm{HisG}_{\mathrm{L}}$ ATPPRTs, ${ }^{16,19}$ and over 27-fold lower than that for L. lactis ATPPRT, ${ }^{28}$ suggesting $\mathrm{PaHisG}_{\mathrm{S}}$ activity is more stringently regulated by this metabolite.

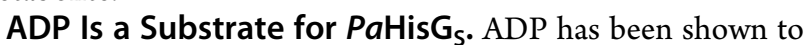
be an inhibitor of $\mathrm{HisG}_{\mathrm{L}}$ ATPPRTs. ${ }^{19}$ However, crystal structures of $\mathrm{PaHis} \mathrm{H}_{\mathrm{S}}$ and $\mathrm{PaATPPRT}$ in complex with PRPP-ADP reveal that ADP binds in the same manner as ATP. ${ }^{29}$ In order to evaluate the ability of $\mathrm{PaHisG}_{\mathrm{S}}$ to use ADP as a substrate, we compared the reactions with ADP and ATP by ${ }^{31} \mathrm{P}$ NMR spectroscopy (Figure S4). The spectra of reactions containing $\mathrm{ADP}$ (Figure S4A) and ATP (Figure S4C) are similar except for the peak at -19.2 to -19.4 corresponding to the $\gamma-\mathrm{PO}_{4}{ }^{2-}$ phosphorus of ATP and PRATP, since this group is absent in $\mathrm{ADP}$ and $N^{1}$-(5-phospho- $\beta$-D-
ribosyl)-ADP (PRADP). Spectra for both reactions differ from the controls lacking $\mathrm{PaHisG}_{\mathrm{S}}$ (Figure S4B,D). The characteristic peak at ca. $3.3 \mathrm{ppm}$ corresponding to the phosphorus in the $N^{1}$-5-phospho- $\beta$-D-ribose moiety of the product ${ }^{26}$ is present in the reaction spectra with ADP (Figure S4A, inset) and ATP (Figure S4C, inset), and absent in the controls (Figure S4B,D, insets), establishing that ADP can replace ATP as a substrate for $\mathrm{PaHisG}_{\mathrm{S}}$.

For a quantitative comparison of the reactions with ATP and $\mathrm{ADP}$, steady-state kinetic analysis of the reaction with either substrate was carried out (Figure 4) and kinetic parameters are

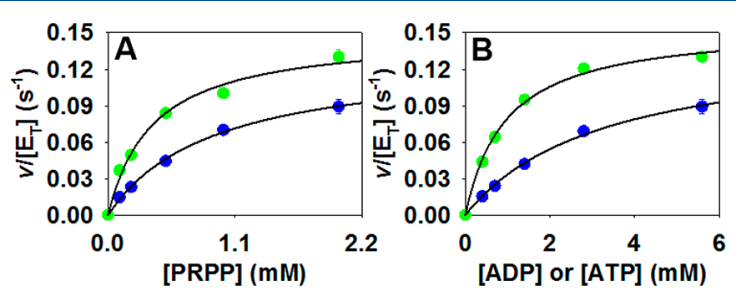

Figure 4. $\mathrm{PaHisG}_{\mathrm{S}}$ substrate saturation curves with either ATP (green) or ADP (blue) as a substrate. (A) Varying PRPP concentration with saturating concentration of the nucleotide. (B) Varying the nucleotide concentration with saturating concentration of PRPP. Data points are mean \pm SE, and lines are data fitting to eq 3 .

summarized in Table S3. Values of $k_{\text {cat }}$ are the same within error with either ATP or ADP as a substrate, indicating that once saturated $\mathrm{PaHisG}_{\mathrm{S}}$ turns over ATP and $\mathrm{ADP}$ just as effectively. The main difference is in the $K_{\mathrm{M}}$ for $\mathrm{ADP}$, which is over 3-fold that for ATP, suggesting some small loss of affinity for the steady-state with ADP.

PaHisG $_{\mathrm{S}}$ and PaATPPRT Kinetics with $\mathrm{Mn}^{2+}$. Replacement of $\mathrm{Mg}^{2+}$ by $\mathrm{Mn}^{2+}$ is a common strategy in enzymology, ${ }^{36}$ having been employed to uncover rate-limiting steps in reactions involving stabilization of phosphate groups. ${ }^{37}$ His $_{\mathrm{L}}$ ATPPRTs have been reported to have their activities either unaltered or decreased by changing the divalent metal in the reaction from the physiological $\mathrm{Mg}^{2+}$ to $\mathrm{Mn}^{2+}$, but no mechanistic inference has been drawn. ${ }^{7,38}$ To evaluate the effect of $\mathrm{Mn}^{2+}$ on a $\mathrm{HisG}_{\mathrm{S}}$ enzyme, saturation curves for $\mathrm{PaHisG}_{\mathrm{S}}$ and $\mathrm{PaATPPRT}$ with either divalent metal were determined (Figure 5), and kinetic constants are displayed in Table S4. $\mathrm{Mn}^{2+}$ led to 2.6- and 11-fold increases in $\mathrm{PaHisG}_{\mathrm{S}}$ $k_{\text {cat }}$ and $k_{\text {cat }} / K_{\mathrm{M}}$ ATP , respectively, as compared with $\mathrm{Mg}^{2+}$. The change in $k_{\text {cat }} / K_{\mathrm{M}}{ }^{\mathrm{ATP}}$ was driven in large part by a reduction in $K_{\mathrm{M}}^{\text {ATP }}$. LC-MS analysis of the $\mathrm{PaHisG}_{\mathrm{S}}$ reaction with $\mathrm{Mn}^{2+}$ confirmed the same product, PRATP, was being formed (Figure S5).

In contrast to $\mathrm{PaHisG}$, steady-state constants for PaATPPRT were unchanged by $\mathrm{Mn}^{2+}$, except for a 2.9-fold increase in $k_{\text {cat }} / K_{\mathrm{M}}{ }^{\text {ATP }}$ owing to a reduction in $K_{\mathrm{M}}{ }^{\text {ATP }}$. These results raise the possibility that $\mathrm{PaHis}_{\mathrm{S}}$ and $\mathrm{PaATPPRT}$ reactions have distinct rate-limiting steps. Crystal structures of $\mathrm{PaHisG}_{\mathrm{S}}$ and $\mathrm{PaATPPRT}$ with various ligands do not depict any specific interaction between $\mathrm{Mg}^{2+}$ and the enzyme, ${ }^{29}$ raising the possibility the off-rates of products from the active site might not be affected by the nature of the metal ion. It is possible, nonetheless, that a solution metal stabilizes charges of either PRATP or $\mathrm{PP}_{\mathrm{i}}$ concomitantly with product release from the enzyme. The metal ion seen in the structures acts as a Lewis acid to stabilize negative charges in the Michaelis complex upon binding of ATP, with a putative second metal 

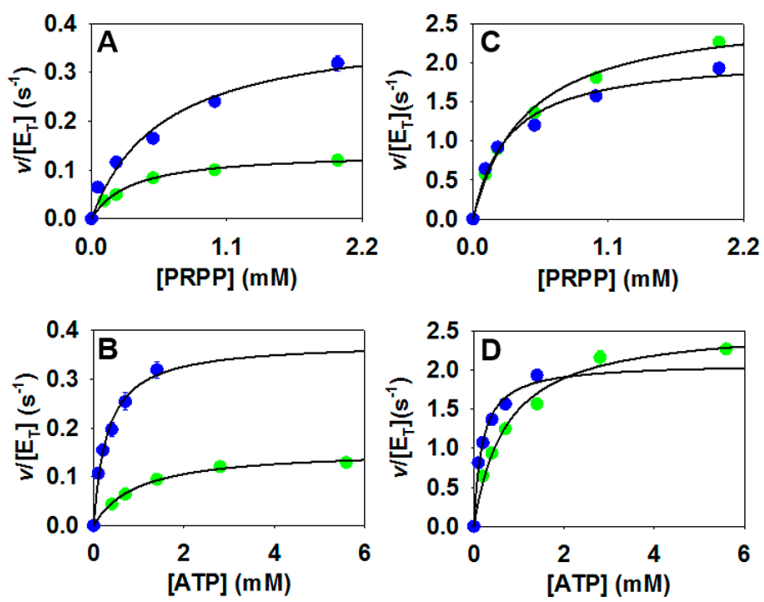

Figure 5. Steady-state kinetics with $\mathrm{Mg}^{2+}$ (green) and $\mathrm{Mn}^{2+}$ (blue). Saturation curves varying either PRPP or ATP concentration with saturating concentration of the cosubstrate for (A and B) $\mathrm{PaHisG}_{S}$ and $(C$ and D) PaATPPRT. Data points are mean $\pm S E$, and lines are data fitting to eq 3 .

ion likely present at the transition state to facilitate departure of the $\mathrm{PP}_{\mathrm{i}}$ leaving group. ${ }^{29}$ Thus, one might expect $\mathrm{Mn}^{2+}$ to increase the reaction rate if rate-limiting steps are located between ATP binding to the enzyme-PRPP complex and product formation, since a stronger Lewis acid would facilitate catalysis by stabilizing charges more efficiently. The kinetic constants affected would be $k_{\text {cat }}$ and $k_{\text {cat }} / K_{\mathrm{M}}$ ATP, which is exactly what is observed with $\mathrm{PaHisG}_{\mathrm{S}}$. If, on the other hand, ternary complex formation played a minor role in limiting the reaction rate, chemistry was fast, and product release was the slowest step, a modest increase in $k_{\text {cat }} / K_{\mathrm{M}}{ }^{\mathrm{ATP}}$ only would be expected, which is the case with PaATPPRT.
A Transition-State Hypothesis for the PaHisG $_{S}$ Reaction. An $S_{N} 1$-like, $D_{N} * A_{N}{ }^{*} 39,40$ transition-state structure has recently been proposed for $C$. jejuni and $M$. tuberculosis $\left(\mathrm{HisG}_{\mathrm{L}}\right.$ ) and L. lactis ( $\mathrm{HisG}_{\mathrm{S}}$ ) ATPPRT-catalyzed reaction based on kinetic isotope effects and computational chemistry, using a simplified model of the reaction for density functional theory calculations. ${ }^{10}$ Having established that $\mathrm{PaHisG}_{\mathrm{S}}$ utilizes $\mathrm{ADP}$ as a substrate with a similar $k_{\text {cat }}$ as it does ATP (Table S3), the crystal structure of the $\mathrm{PaHisG}_{\mathrm{S}}$-PRPP-Mg-ADP Michaelis complex ${ }^{29}$ served as a starting point for density functional theory calculations in order to find a theoretical transition state for the reaction that includes not only the full substrates but also several active-site residue side-chain surrogates and water molecules essential to stabilize the system, with either $\mathrm{Mg}^{2+}$ or $\mathrm{Mn}^{2+}$ as the metal ion (Figure 6). Transition structures were located as stationary points (i.e., without any constraints on distances or dihedral angles) and possess only one imaginary frequency reflecting vibration along the $\mathrm{N} 1-\mathrm{C} 1-\mathrm{O} 1$ axis. Inclusion of a second equivalent of the divalent metal ion to stabilize the departing $\mathrm{PP}_{\mathrm{i}}$ leaving group was essential to locate transition structures, lending support to a recent proposal based on the crystal structures of $\mathrm{PaHisG}_{\mathrm{S}}$ and PaATPPRT Michaelis complexes ${ }^{29}$ and the transition structures of other phosphoribosyltransferases. ${ }^{41}$

The optimized structures indicate an $S_{N} 2$-like, almost synchronous $\mathrm{A}_{\mathrm{N}} \mathrm{D}_{\mathrm{N}}$ transition state is possible for the $\mathrm{PaHis}_{\mathrm{S}}$-catalyzed reaction with either $\mathrm{Mg}^{2+}$ (Figure 6A) or $\mathrm{Mn}^{2+}$ (Figure 6B) as a Lewis acid. The $6-\mathrm{NH}_{2}$ group of ADP is protonated in all transition structures and is likely to lose a proton to form the 6-NH group of PRADP only after the nucleophilic substitution is complete, as recently hypothesized. $^{29}$ Nucleophilic attack occurs from the charge-neutral resonance structure of adenine in which $\mathrm{N} 1$ has transiently a negative charge due to electron donation from N6. This natural resonance structure represents $6.64 \%$ of the distribu-
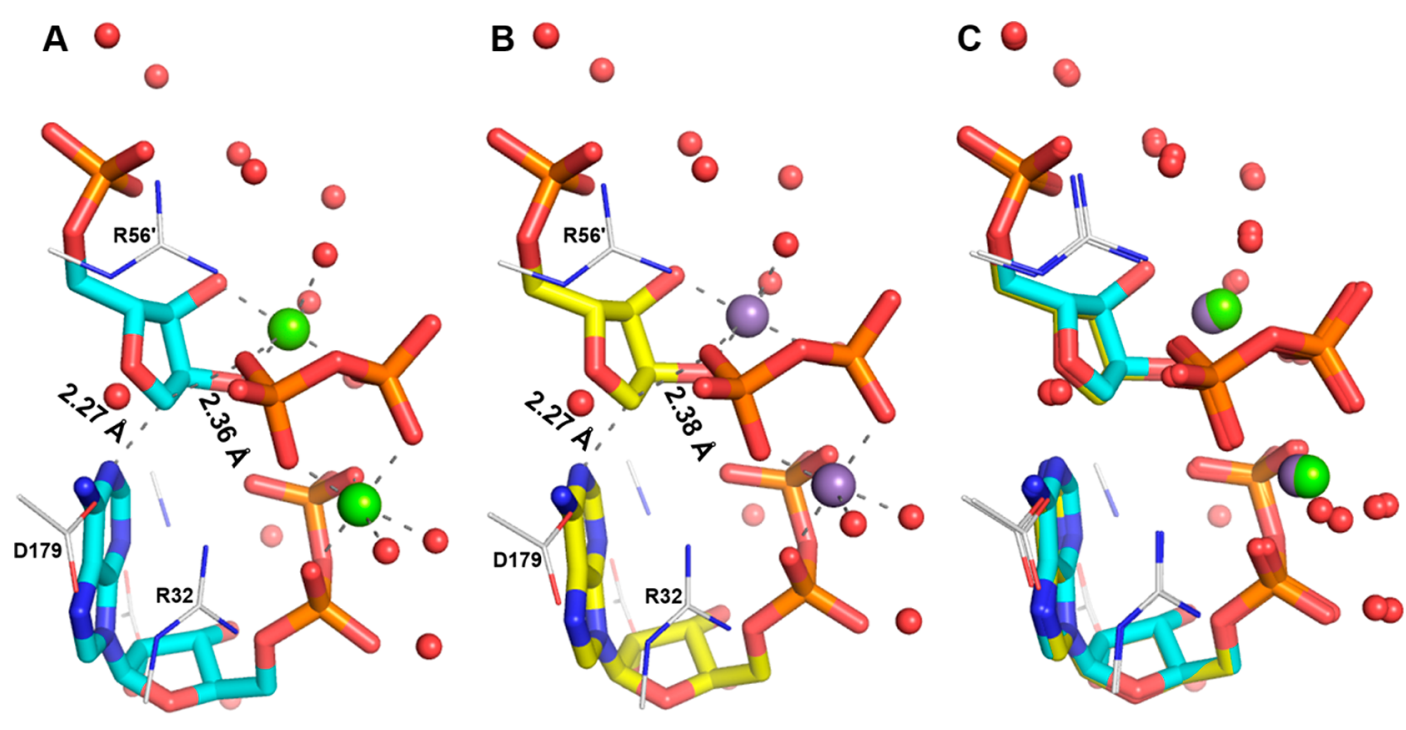

$\odot$

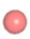

$\odot$

Figure 6. Transition-state model for the $\mathrm{PaHisG}_{\mathrm{S}}$-catalyzed reaction. (A) Transition structure with magnesium, (B) transition structure with manganese, and (C) overlay of the transition structures with magnesium and manganese. Substrates are represented as stick models, side-chain mimics as wireframe, and metal ions and water oxygens as spheres. Carbon is in either cyan or yellow for substrates and in gray for side-chain mimics, with oxygen in red, nitrogen in blue, phosphorus in orange, magnesium in green, and manganese in purple. Hydrogens are omitted for simplicity. Partial bonds and metal ion coordination bonds are represented by dashed lines. Distances are shown for the N1-C1 and the $\mathrm{C} 1-\mathrm{O} 1$ bonds. Key residue side-chain mimics are labeled, and the prime denotes a residue of the adjacent subunit in the $P a H_{i s} G_{S}$ dimer. ${ }^{29}$ 
tion of adenine resonances. ${ }^{42}$ The $A_{N} D_{N}$ transition state located here contrasts with the $\mathrm{D}_{\mathrm{N}} * \mathrm{~A}_{\mathrm{N}}{ }^{*}$ one proposed for $\mathrm{HisG}_{\mathrm{L}}$ and $\mathrm{HisG}_{\mathrm{S}}$ ATPPRT reaction. ${ }^{10}$ This would mean that different orthologues of ATPPRT catalyze the same reaction via different transition states, which is not uncommon in ribosyl-transfer reactions. For instance, distinct transition-state models based on kinetic isotope effects and density functional theory have been suggested for bovine and human purine nucleoside phosphorylases, ${ }^{43,44}$ and for wild-type and mutant human purine nucleoside phosphorylases. ${ }^{43,45}$ Kinetic isotope effect measurements for $P a H_{i s} G_{S}$ could test the $A_{N} D_{N}$ transition-state hypothesis put forth in this work.

Overlay of the transition structures with $\mathrm{Mg}^{2+}$ and $\mathrm{Mn}^{2+}$ demonstrates an almost identical arrangement (Figure 6C), indicating transition-state geometry cannot explain the discrimination in $\mathrm{PaHisG}_{\mathrm{S}}$ reactivity between the metal ions. Natural bond orbital (NBO) analysis of the transition structures, however, revealed significant differences in charge distribution in the metal ions and the $\mathrm{PP}_{\mathrm{i}}$ at the transition state depending on which metal is included (Table S5). Most atoms have very similar charges in the two transition structures, except for the metal ions and $\mathrm{PP}_{\mathrm{i}}$ oxygens. The average charge of the two magnesium ions at the transition state is 1.439 , over 2 -fold higher than the average charge of the manganese ions, 0.649 . This is due to more efficient attenuation of the negative charge of the $\mathrm{PP}_{\mathrm{i}}$ leaving group by $\mathrm{Mn}^{2+}$ through $d$-orbital bonding to coordinating oxygens, as shown by orbital population analysis. As compared with $\mathrm{Mg}^{2+}$, therefore, $\mathrm{Mn}^{2+}$ improves catalysis in the $\mathrm{PaHisG}_{\mathrm{S}}$ reaction by more effectively stabilizing the negatively charged leaving group at the transition state.

Solvent Viscosity Effects on $\mathrm{PaHisG}_{\mathrm{s}}$ and PaATPPRT Kinetics. In order to probe further the distinct rate-limiting steps governing $\mathrm{PaHis} \mathrm{G}_{\mathrm{S}}$ and $\mathrm{PaATPPRT}$ catalyses, the effect of solvent viscosity on reaction rates was evaluated (Figure 7), and the data are summarized in Tables S6 and S7. Increasing solvent viscosity by increasing glycerol concentration ${ }^{46}$ slows down diffusional steps such as substrate binding and release and product release, and values of kinetic constants will be reduced if such steps are rate-limiting. ${ }^{47-49} \mathrm{PaHisG}_{\mathrm{S}}$ rate constants did not decrease with increasing glycerol concentration (Table S6), consistent with diffusional steps not contributing to limit the reaction rate. Instead, as shown in Figure 7A and Table S6, glycerol led to an increase in $\mathrm{PaHisG}_{\mathrm{S}}$ $k_{\text {cat }}$ and $k_{\text {cat }} / K_{\mathrm{M}}{ }^{\mathrm{PRPP}}$ of up to 2.7 - and 2.4-fold, respectively, while $k_{\text {cat }} / K_{\mathrm{M}}{ }^{\mathrm{ATP}}$ was only marginally affected. Inverse solvent viscosity effects generally suggest that a more active dynamic conformation of the enzyme or the Michaelis complex is favored at high viscosity. ${ }^{47-49}$ To rule out the possibility that glycerol might be affecting the overall stability of the enzyme, a thermal denaturation curve was determined by DSF in $22 \%$ glycerol (Figure S6), and no difference in $T_{\mathrm{m}}$ was observed in comparison with that determined without glycerol (Table S2). Crystal structures of $\mathrm{PaHisG}_{\mathrm{S}}$ apoenzyme and $\mathrm{PaHisG}_{\mathrm{S}}$-PRPPATP were also obtained with and without soaking crystals in glycerol, and no electron density for glycerol was visualized in any of the structures. ${ }^{29}$ This suggests that glycerol is acting as part of bulk solvent, not as a ligand, but with the caveat that crystal lattice might have prevented binding.

To assess the effect of solvent viscosity on PaATPPRT, first the $K_{\mathrm{D}}$ for the $\mathrm{PaHisG}_{\mathrm{S}}-\mathrm{PaHisZ}$ complex had to be measured in glycerol (Figure S7), and data fitting to eq 1 yielded $K_{\mathrm{D}}$ 's of $1.3 \pm 0.1,1.1 \pm 0.2$, and $0.5 \pm 0.1 \mu \mathrm{M}$ in $0 \%, 18 \%$, and $27 \%$
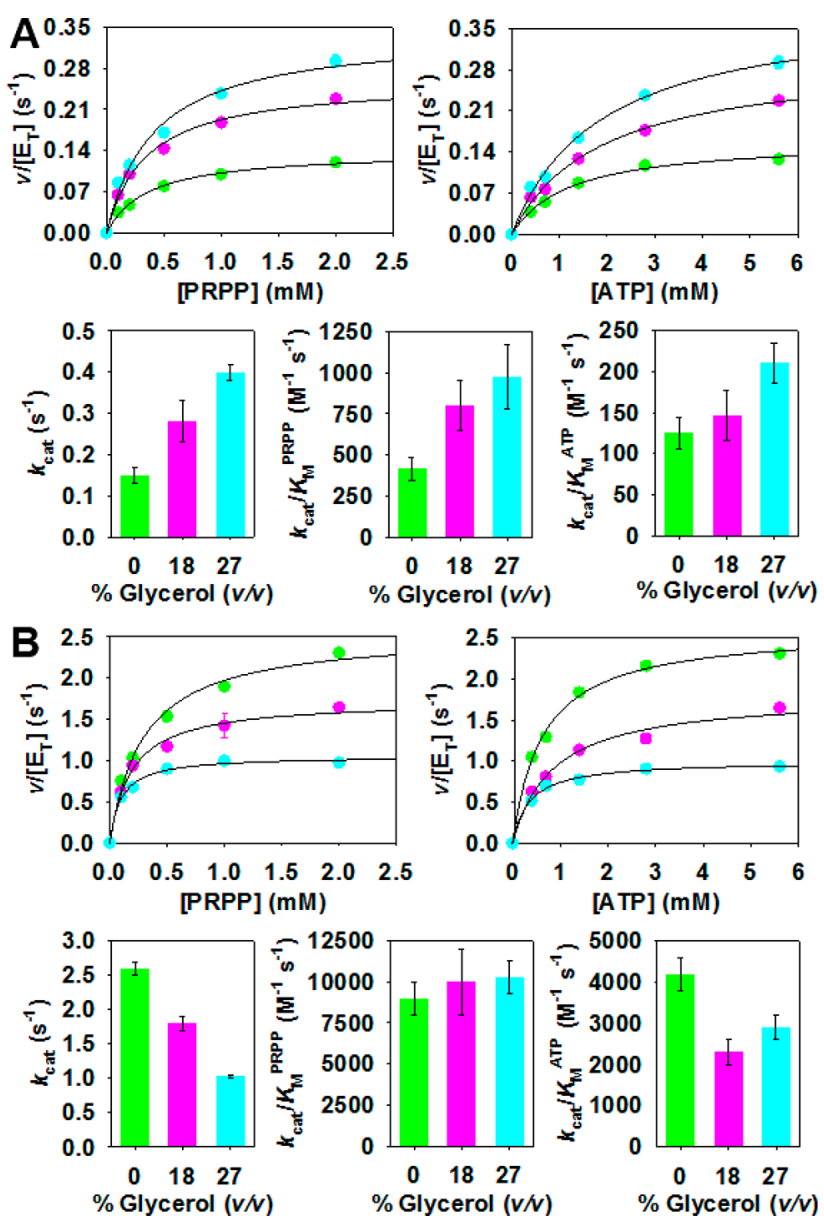

Figure 7. Solvent viscosity effects on steady-state kinetics determined at $0 \%$ (green), $18 \%$ (pink), and $27 \%$ (cyan) glycerol (v/v). (A) $\mathrm{PaHisG}_{\mathrm{S}}$ saturation curves (top) and steady-state constants (bottom) dependence on glycerol concentration. (B) PaATPPRT saturation curves (top) and steady-state constants (bottom) dependence on glycerol concentration. Data represent either mean \pm SE (scatter plots) or value \pm fitting error (bar plots). Lines are data fitting to eq 3 .

glycerol, respectively. Knowledge of the $K_{\mathrm{D}}$ 's allowed calculation, using eq 2, of PaATPPRT concentrations at different glycerol concentrations for measurement of $k_{\text {cat }}$. In contrast to the effect on $\mathrm{PaHisG}_{\mathrm{S}}$, increasing solvent viscosity resulted in a decrease of up to 2.5 -fold in PaATPPRT $k_{\text {cat }}$ with negligible effects on $k_{\text {cat }} / K_{\mathrm{M}}$ for either substrate, as shown in Figure 7B and Table S7. This points to product dissociation from $\mathrm{PaATPPRT}$ as the rate-limiting step in the reaction, as is the case with $\mathrm{HisG}_{\mathrm{L}}$ ATPPRTs. ${ }^{8,50}$

Burst in Product Formation by PaATPPRT. To glean additional support for distinct rate-limiting steps controlling nonactivated and activated $P a H_{i s} G_{S}$ reactions, product formation time courses were monitored under pre-steadystate conditions for $\mathrm{PaHisG}_{\mathrm{S}}$ and $\mathrm{PaATPPRT}$ (Figure 8). PRATP formation with $\mathrm{PaHis} \mathrm{G}_{\mathrm{S}}$ varies linearly with time with a steady-state rate constant of $0.091 \pm 0.001 \mathrm{~s}^{-1}$, in reasonable agreement with $k_{\text {cat }}$ (Tables S3, S4, S6). This rules out a slow step after formation of enzyme-bound products ${ }^{51}$ and suggests interconversion between ternary complexes $\left(k_{5}+k_{6}\right.$ in Scheme 2) is rate-limiting.

On the other hand, a burst in PRATP formation precedes the steady-state with PaATPPRT, and data fitting to eq 7 yielded a $k_{\text {burst }}$ of $80 \pm 1 \mathrm{~s}^{-1}$, a steady-state rate constant of 


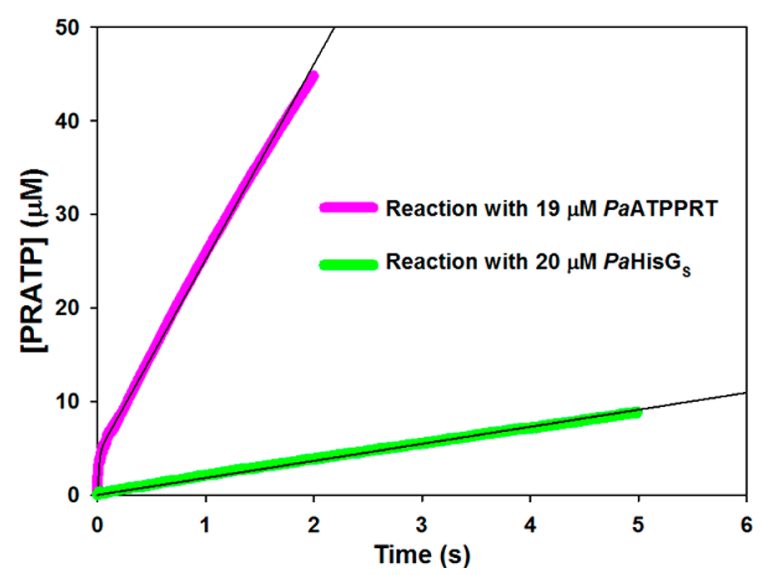

Figure 8. Pre-steady-state kinetics with $\mathrm{PaATPPRT}$ and $\mathrm{PaHisG}$ with a burst in product formation observed with the former but not the latter. Black lines are data fitting to eq 7 for PaATPPRT and a linear regression for $\mathrm{PaHisG}_{\mathrm{S}}$.

Scheme 2. Interpretation of the Pre-Steady-State of $\mathrm{PaHisG}_{\mathrm{S}}$ and PaATPPRT Reactions

$$
\text { E-PRPP-ATP } \frac{k_{5}}{k_{6}} \text { E-PRATP-PP } \stackrel{\mathrm{PP}_{\mathrm{i}}+\mathrm{PRATP}_{7}^{\prime}}{\longrightarrow} \mathrm{E}
$$

$1.11 \pm 0.01 \mathrm{~s}^{-1}$, and an $A_{0}$ of $4.3 \mu \mathrm{M}$. This is consistent with a step after chemistry, likely product release $\left(k^{\prime}{ }_{7}\right.$ in Scheme 2$)$, limiting the reaction rate, ${ }^{51,52}$ in agreement with the conclusion drawn from solvent viscosity effects. $M$. tuberculosis His $_{\mathrm{L}}$ ATPPRT also displays a burst in product formation with a $k_{\text {burst }}$ of $0.67 \mathrm{~s}^{-1}$ at $25{ }^{\circ} \mathrm{C}$. ${ }^{8}$ Thus, PaATPPRT $k_{\text {burst }}$ at $20{ }^{\circ} \mathrm{C}$ is over 119-fold higher than M. tuberculosis $\mathrm{HisG}_{\mathrm{L}}$ ATPPRT's at $25{ }^{\circ} \mathrm{C}$, which may be a feature of $\mathrm{HisG}_{\mathrm{S}}$ ATPPRTs and/or a consequence of PaATPPRT being psychrophilic. ${ }^{26}$

The amplitude of the burst phase $\left(A_{0}\right)$ generally reflects the concentration of the Michaelis complex, which at saturating substrate concentrations could be as high as the concentration of enzyme. ${ }^{53}$ The $A_{0}$ of $4.3 \mu \mathrm{M}$ is over 4.4 -fold lower than the concentration of PaATPPRT used in the experiment $(19 \mu \mathrm{M})$. Two main reasons may account, separately or in combination, for this result without invoking the unlikely scenario where ca. $75 \%$ of enzyme molecules are inactive. First, the enzyme might not be fully saturated by one or both substrates, which would also explain the steady-state rate constant being slightly smaller than the $k_{\text {cat }}$ values extrapolated from substrate saturation curves. This may be the case with the $\mathrm{PaHisG}_{\mathrm{S}}$ steady-state rate constant as well. Second, chemical reversibility decreases $A_{0}$. Both $k_{\text {burst }}$ and $A_{0}$ are dependent on all rate constants depicted in Scheme 2, the forward and reverse rate constants for interconversion between enzyme-bound substrates and products, $k_{5}$ and $k_{6}$, respectively, and the net rate constant for release of products from the enzyme, $k^{\prime}$, according to eqs 9 and $10 .^{51}$

$$
\begin{aligned}
& k_{\text {burst }}=k_{5}+k_{6}+k^{\prime}{ }_{7} \\
& A_{0}=\frac{k_{5}\left(k_{6}+k^{\prime}{ }_{7}\right)}{\left(k_{5}+k_{6}+k^{\prime}\right)^{2}}
\end{aligned}
$$

Upon inspection of eqs 9 and 10, one must conclude that under the most favorable conditions, full expression of $A_{0}$ can only occur when chemistry is irreversible $\left(k_{6}=0\right)$ and much faster than product release $\left(k_{5} \gg k^{\prime}{ }_{7}\right)$. Internal reversibility, described by the magnitude of $k_{6}$, will increase $k_{\text {burst }}$ while decreasing $A_{0}$. Equilibrium in the ATPPRT reaction strongly favors the reactants, ${ }^{17}$ making it possible for the crystal structure of the PaATPPRT-PRPP-ATP ternary-complex to be attained with wild-type enzyme. ${ }^{29}$ Hence, $k_{6}$ is likely to be much larger than $k_{5}$, making $k_{6}$ the main contributor to $k_{\text {burst }}$ and significantly reducing $A_{0}$ from its theoretical upper limit of $19 \mu \mathrm{M}$. Relative contributions of $k_{5}$ and $k_{6}$ to $k_{\text {burst }}$ and $A_{0}$ notwithstanding, it is clear that activation of $\mathrm{PaHisG}_{\mathrm{S}}$ by $\mathrm{PaHisZ}$ switches the rate-limiting step of the reaction from interconversion between the ternary complexes to product release.

PaHisZ-Induced Shift in the Rate-Limiting Step. The results presented here demonstrate that two long-established mechanistic features of $\mathrm{His}_{\mathrm{L}}$ ATPPRTs, namely, ATP as the first substrate to bind to the enzyme and $\mathrm{ADP}$ as an

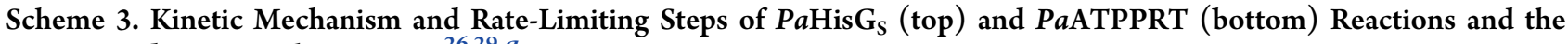
Corresponding Crystal Structures ${ }^{26,29} a$

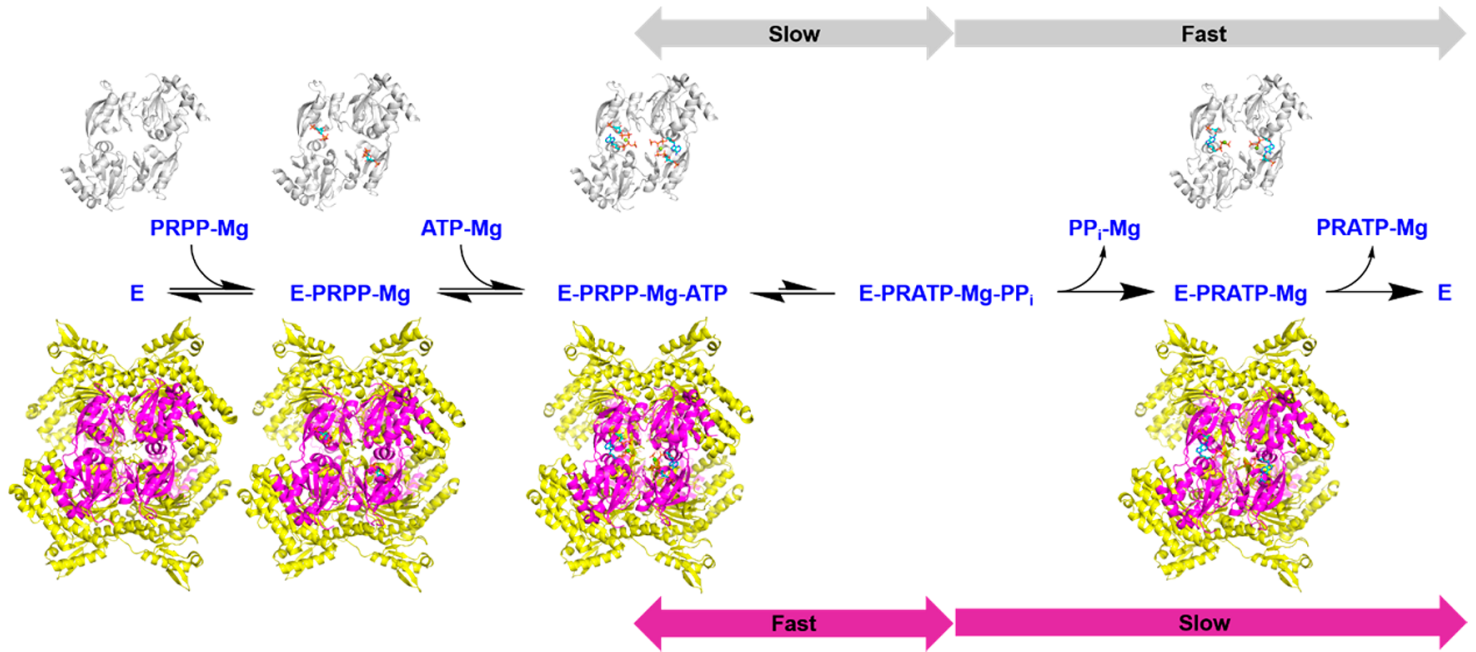

${ }^{a_{\text {The }}}$ second $\mathrm{PaHis} \mathrm{G}_{\mathrm{S}}$ homodimers lie behind the $\mathrm{PaHisZ}$ tetramers. 
inhibitor, ${ }^{16,19,21,22,33}$ do not apply to $\mathrm{PaHisG}_{\mathrm{S}}$, and possibly other $\mathrm{HisG}_{\mathrm{S}}$ ATPPRTs. Providing functional data to support hypotheses proposed based on extensive crystallography work on $\mathrm{PaHisG}_{\mathrm{S}}$ and $\mathrm{PaATPPRT},{ }^{29} \mathrm{PaHisG}_{\mathrm{S}}$ is shown to be able to replace $\mathrm{ATP}$ for $\mathrm{ADP}$ as a substrate and to operate by a steadystate ordered mechanism where PRPP is the first substrate to bind to the enzyme (Scheme 3). $P a H_{i s} G_{S} k_{\text {cat }}$ increases when $\mathrm{Mn}^{2+}$ replaces $\mathrm{Mg}^{2+}$, which can be accounted for owing to more efficient charge stabilization by $\mathrm{Mn}^{2+}$ upon leaving group departure at the transition state. The observation that PaATPPRT steady-state kinetics is unaltered with $\mathrm{Mn}^{2+}$ raises the possibility of $k_{\text {cat }}$ 's for the activated and nonactivated enzyme forms reporting on distinct steps. This is confirmed by solvent viscosity effects on steady-state parameters and by presteady-state kinetics under multiple-turnover conditions, which indicate that interconversion between $\mathrm{PaHisG}_{\mathrm{S}}-\mathrm{PRPP}$-ATP and $\mathrm{PaHisG}_{\mathrm{S}}-\mathrm{PRATP}-\mathrm{PP}_{\mathrm{i}}$ complexes limits the reaction rate for the nonactivated enzyme, likely with a significant contribution from chemistry given the effect of $\mathrm{Mn}^{2+}$. However, allosteric activation by $\mathrm{PaHisZ}$ accelerates this interconversion well beyond the steady-state rate, which now reflects the off-rate of either $\mathrm{PP}_{\mathrm{i}}$ from the PaATPPRTPRATP-PP $_{i}$ ternary complex or PRATP from the PaATPPRT-PRATP binary complex (Scheme 3 ). This provides fundamental insight into the allosteric regulation of a complex multiprotein enzyme.

\section{ASSOCIATED CONTENT}

\section{S Supporting Information}

The Supporting Information is available free of charge on the ACS Publications website at DOI: 10.1021/acs.biochem.8b00559.

ITC curves, $\mathrm{PaHisG}_{\mathrm{S}}$ inhibition by AMP, spectra, DSFbased thermal denaturation of $\mathrm{PaHisG}_{\mathrm{S}}$, determination of equilibrium dissociation, $\mathrm{PaATPPRT}$ and $\mathrm{PaHisG}_{\mathrm{S}}$ steady-state parameters from initial velocity patterns, $\mathrm{PaHisG}_{\mathrm{S}} \mathrm{T}_{\mathrm{m}}$ 's by DSF in the presence and absence of ligands, steady-state kinetic constants, effect of $\mathrm{Mn}^{2+}$ on PaATPPRT and $\mathrm{PaHisG}_{\mathrm{S}}$ steady-state kinetic parameters, NBO charge distribution, solvent viscosity effects, and coordinates for all transition structures (PDF)

\section{AUTHOR INFORMATION}

\section{Corresponding Authors}

*E-mail: jhirschi@binghamton.edu.

*E-mail: rgds@st-andrews.ac.uk. Phone: +44 01334463496.

ORCID $\odot$

Rafael G. da Silva: 0000-0002-1308-8190

Notes

The authors declare no competing financial interest.

\section{ACKNOWLEDGMENTS}

This work was supported by a Wellcome Trust Institutional Strategic Support Fund to the University of St Andrews and the Biotechnology and Biological Sciences Research Council (BBSRC) [grant no. BB/M010996/1] via an EASTBIO Doctoral Training Partnership studentship to G.F. The computational work used the Extreme Science and Engineering Discovery Environment (XSEDE) resource comet at the SDSC through allocation CHE150007, supported by the National Science Foundation [grant no. ACI-1548562]. R.S. was the recipient of an Erasmus Undergraduate Fellowship. The authors thank Dr. Eoin R. Gould for his assistance with ${ }^{31} \mathrm{P}$ NMR experiments.

\section{ABBREVIATIONS}

ATP, adenosine 5'-triphosphate; AMP, adenosine 5'-monophosphate; ADP, adenosine 5'-diphosphate; ATPPRT, ATP phosphoribosyltransferase; PRPP, 5-phospho- $\alpha$-D-ribosyl-1-pyrophosphate; PRATP, $N^{1}$-(5-phospho- $\beta$-D-ribosyl)-ATP; $\mathrm{PP}_{\mathrm{i}}$, inorganic pyrophosphate; DTT, dithiothreitol; ITC, isothermal titration calorimetry; DSF, differential scanning fluorimetry; LC-MS, liquid chromatography-mass spectrometry; PaATPPRT, $P$. arcticus ATPPRT; $P a \mathrm{HisG}_{\mathrm{S}}, P$. arcticus $\mathrm{HisG}_{\mathrm{S}} ; \quad \mathrm{PaHisZ}, \quad P$. arcticus HisZ; ${ }^{31} \mathrm{P}$ NMR, ${ }^{31} \mathrm{P}$ nuclear magnetic resonance; MtPPase, Mycobacterium tuberculosis inorganic pyrophosphatase; MWCO, molecular weight cut off; ESI-MS, electrospray ionization mass spectrometry; $K_{\mathrm{D}}$, equilibrium dissociation constant; EcPRPPS, E. coli PRPP synthetase; PRADP, $N^{1}$-(5-phospho- $\beta$-D-ribosyl)-ADP

\section{REFERENCES}

(1) Barends, T. R., Dunn, M. F., and Schlichting, I. (2008) Tryptophan synthase, an allosteric molecular factory. Curr. Opin. Chem. Biol. 12, 593-600.

(2) Fan, Y., Cross, P. J., Jameson, G. B., and Parker, E. J. (2018) Exploring modular allostery via interchangeable regulatory domains. Proc. Natl. Acad. Sci. U. S. A. 115, 3006-3011.

(3) Pisco, J. P., de Chiara, C., Pacholarz, K. J., Garza-Garcia, A., Ogrodowicz, R. W., Walker, P. A., Barran, P. E., Smerdon, S. J., and de Carvalho, L. P. S. (2017) Uncoupling conformational states from activity in an allosteric enzyme. Nat. Commun. 8, 203.

(4) de Carvalho, L. P., Argyrou, A., and Blanchard, J. S. (2005) Slowonset feedback inhibition: Inhibition of mycobacterium tuberculosis alpha-isopropylmalate synthase by l-leucine. J. Am. Chem. Soc. 127, 10004-10005.

(5) Buller, A. R., Brinkmann-Chen, S., Romney, D. K., Herger, M., Murciano-Calles, J., and Arnold, F. H. (2015) Directed evolution of the tryptophan synthase beta-subunit for stand-alone function recapitulates allosteric activation. Proc. Natl. Acad. Sci. U. S. A. 112, 14599-14604.

(6) Schendzielorz, G., Dippong, M., Grunberger, A., Kohlheyer, D., Yoshida, A., Binder, S., Nishiyama, C., Nishiyama, M., Bott, M., and Eggeling, L. (2014) Taking control over control: Use of product sensing in single cells to remove flux control at key enzymes in biosynthesis pathways. ACS Synth. Biol. 3, 21-29.

(7) Cramer, J. T., Führing, J. I., Baruch, P., Brütting, C., Knölker, H.J., Gerardy-Schahn, R., and Fedorov, R. (2018) Decoding allosteric networks in biocatalysts: Rational approach to therapies and biotechnologies. ACS Catal. 8, 2683-2692.

(8) Pedreno, S., Pisco, J. P., Larrouy-Maumus, G., Kelly, G., and de Carvalho, L. P. (2012) Mechanism of feedback allosteric inhibition of atp phosphoribosyltransferase. Biochemistry 51, 8027-8038.

(9) Ames, B. N., Martin, R. G., and Garry, B. J. (1961) The first step of histidine biosynthesis. J. Biol. Chem. 236, 2019-2026.

(10) Moggre, G. J., Poulin, M. B., Tyler, P. C., Schramm, V. L., and Parker, E. J. (2017) Transition state analysis of adenosine triphosphate phosphoribosyltransferase. ACS Chem. Biol. 12, 26622670.

(11) Cho, Y., Sharma, V., and Sacchettini, J. C. (2003) Crystal structure of atp phosphoribosyltransferase from mycobacterium tuberculosis. J. Biol. Chem. 278, 8333-8339.

(12) Cho, Y., Ioerger, T. R., and Sacchettini, J. C. (2008) Discovery of novel nitrobenzothiazole inhibitors for mycobacterium tuberculosis atp phosphoribosyl transferase (hisg) through virtual screening. J. Med. Chem. 51, 5984-5992.

(13) Kulis-Horn, R. K., Persicke, M., and Kalinowski, J. (2015) Corynebacterium glutamicum atp-phosphoribosyl transferases suit- 
able for 1-histidine production-strategies for the elimination of feedback inhibition. J. Biotechnol. 206, 26-37.

(14) Kulis-Horn, R. K., Persicke, M., and Kalinowski, J. (2014) Histidine biosynthesis, its regulation and biotechnological application in corynebacterium glutamicum. Microb. Biotechnol. 7, 5-25.

(15) Pacholarz, K. J., Burnley, R. J., Jowitt, T. A., Ordsmith, V., Pisco, J. P., Porrini, M., Larrouy-Maumus, G., Garlish, R. A., Taylor, R. J., de Carvalho, L. P. S., and Barran, P. E. (2017) Hybrid mass spectrometry approaches to determine how 1-histidine feedback regulates the enzyzme mtatp-phosphoribosyltransferase. Structure 25, $730-738$.

(16) Mittelstadt, G., Moggre, G. J., Panjikar, S., Nazmi, A. R., and Parker, E. J. (2016) Campylobacter jejuni adenosine triphosphate phosphoribosyltransferase is an active hexamer that is allosterically controlled by the twisting of a regulatory tail. Protein Sci. 25, 14921506.

(17) Bell, R. M., and Koshland, D. E. (1971) Allosteric properties of the first enzyme of the histidine operon. Bioorg. Chem. 1, 409-423.

(18) Martin, R. G. (1963) The first enzyme in histidine biosynthesis: The nature of feedback inhibition by histidine. J. Biol. Chem. 238, 257-268.

(19) Morton, D. P., and Parsons, S. M. (1977) Inhibition of atp phosphoribosyltransferase by amp and adp in the absence and presence of histidine. Arch. Biochem. Biophys. 181, 643-648.

(20) Livingstone, E. K., Mittelstadt, G., Given, F. M., and Parker, E. J. (2016) Independent catalysis of the short form hisg from lactococcus lactis. FEBS Lett. 590, 2603-2610.

(21) Morton, D. P., and Parsons, S. M. (1976) Biosynthetic direction substrate kinetics and product inhibition studies on the first enzyme of histidine biosynthesis, adenosine triphosphate phosphoribosyltransferase. Arch. Biochem. Biophys. 175, 677-686.

(22) Kleeman, J. E., and Parsons, S. M. (1976) Reverse direction substrate kinetics and inhibition studies on the first enzyme of histidine biosynthesis, adenosine triphosphate phosphoribosyltransferase. Arch. Biochem. Biophys. 175, 687-693.

(23) Sissler, M., Delorme, C., Bond, J., Ehrlich, S. D., Renault, P., and Francklyn, C. (1999) An aminoacyl-trna synthetase paralog with a catalytic role in histidine biosynthesis. Proc. Natl. Acad. Sci. U. S. A. 96, 8985-8990.

(24) Vega, M. C., Zou, P., Fernandez, F. J., Murphy, G. E., Sterner, R., Popov, A., and Wilmanns, M. (2005) Regulation of the heterooctameric atp phosphoribosyl transferase complex from thermotoga maritima by a trna synthetase-like subunit. Mol. Microbiol. 55, 675686.

(25) Bovee, M. L., Champagne, K. S., Demeler, B., and Francklyn, C. S. (2002) The quaternary structure of the hisz-hisg n-1-(5'phosphoribosyl)-atp transferase from lactococcus lactis. Biochemistry $41,11838-11846$.

(26) Stroek, R., Ge, Y., Talbot, P. D., Glok, M. K., Bernas, K. E., Thomson, C. M., Gould, E. R., Alphey, M. S., Liu, H., Florence, G. J., Naismith, J. H., and da Silva, R. G. (2017) Kinetics and structure of a cold-adapted hetero-octameric atp phosphoribosyltransferase. Biochemistry 56, 793-803.

(27) Champagne, K. S., Sissler, M., Larrabee, Y., Doublie, S., and Francklyn, C. S. (2005) Activation of the hetero-octameric atp phosphoribosyl transferase through subunit interface rearrangement by a trna synthetase paralog. J. Biol. Chem. 280, 34096-34104.

(28) Champagne, K. S., Piscitelli, E., and Francklyn, C. S. (2006) Substrate recognition by the hetero-octameric atp phosphoribosyltransferase from lactococcus lactis. Biochemistry 45, 14933-14943.

(29) Alphey, M. S., Fisher, G., Ge, Y., Gould, E. R., Machado, T. G., Liu, H., Florence, G. J., Naismith, J. H., and da Silva, R. G. (2018) Catalytic and anticatalytic snapshots of a short-form atp phosphoribosyltransferase. ACS Catal. 8, 5601-5610.

(30) Smith, D. W., and Ames, B. N. (1965) Phosphoribosyladenosine monophosphate, an intermediate in histidine biosynthesis. J. Biol. Chem. 240, 3056-3063.

(31) Frisch, M. J., Trucks, G. W., Schlegel, H. B., Scuseria, G. E., Robb, M. A., Cheeseman, J. R., Scalmani, G., Barone, V., Mennucci,
B., Petersson, G. A., Nakatsuji, H., Caricato, M., Li, X., Hratchian, H. P., Izmaylov, A. F., Bloino, J., Zheng, G., Sonnenberg, J. L., Hada, M., Ehara, M., Toyota, K., Fukuda, R., Hasegawa, J., Ishida, M., Nakajima, T., Honda, Y., Kitao, O., Nakai, H., Vreven, T., Montgomery, J. A., Jr., Peralta, J. E., Ogliaro, F., Bearpark, M. J., Heyd, J. J., Brothers, E. N., Kudin, K. N., Staroverov, V. N., Kobayashi, R., Normand, J., Raghavachari, K., Rendell, A. P., Burant, J. C., Iyengar, S. S., Tomasi, J., Cossi, M., Rega, N., Millam, J. M., Klene, M., Knox, J. E., Cross, J. B., Bakken, V., Adamo, C., Jaramillo, J., Gomperts, R., Stratmann, R. E., Yazyev, O., Austin, A. J., Cammi, R., Pomelli, C., Ochterski, J. W., Martin, R. L., Morokuma, K., Zakrzewski, V. G., Voth, G. A., Salvador, P., Dannenberg, J. J., Dapprich, S., Daniels, A. D., Farkas, O., Foresman, J. B., Ortiz, J. V., Cioslowski, J., and Fox, D. J. (2009), Gaussian 09, Gaussian Inc., Wallingford, CT.

(32) Niesen, F. H., Berglund, H., and Vedadi, M. (2007) The use of differential scanning fluorimetry to detect ligand interactions that promote protein stability. Nat. Protoc. 2, 2212-2221.

(33) Mittelstadt, G., Jiao, W., Livingstone, E. K., Moggre, G. J., Nazmi, A. R., and Parker, E. J. (2018) A dimeric catalytic core relates the short and long forms of atp-phosphoribosyltransferase. Biochem. J. 475, 247-260.

(34) Cleland, W. W. (1967) Enzyme kinetics. Annu. Rev. Biochem. $36,77-112$.

(35) Lohkamp, B., McDermott, G., Campbell, S. A., Coggins, J. R., and Lapthorn, A. J. (2004) The structure of escherichia coli atpphosphoribosyltransferase: Identification of substrate binding sites and mode of amp inhibition. J. Mol. Biol. 336, 131-144.

(36) Wang, Z., and Cole, P. A. (2014) Catalytic mechanisms and regulation of protein kinases. Methods Enzymol. 548, 1-21.

(37) Grace, M. R., Walsh, C. T., and Cole, P. A. (1997) Divalent ion effects and insights into the catalytic mechanism of protein tyrosine kinase csk. Biochemistry 36, 1874-1881.

(38) Zhang, Y., Shang, X., Deng, A., Chai, X., Lai, S., Zhang, G., and Wen, T. (2012) Genetic and biochemical characterization of corynebacterium glutamicum atp phosphoribosyltransferase and its three mutants resistant to feedback inhibition by histidine. Biochimie 94, 829-838.

(39) Guthrie, R. D., and Jencks, W. P. (1989) Iupac recommendations for the representation of reaction mechanisms. Acc. Chem. Res. 22, 343-349.

(40) In IUPAC recommendation for reaction mechanism nomenclature (see ref 39), $A_{N} D_{N}$ describes an associative nucleophilic substitution reaction mechanism where the electrophile is partially bonded to both incoming nucleophile and departing leaving group at the transition state. $\mathrm{D}_{\mathrm{N}} * \mathrm{~A}_{\mathrm{N}}^{*}$ describes a dissociative nucleophilic substitution reaction mechanism where the leaving group departs to form an intermediate, and the highest-energy transition state is the one for subsequent nucleophilic attack to the intermediate.

(41) Burgos, E. S., Vetticatt, M. J., and Schramm, V. L. (2013) Recycling nicotinamide. The transition-state structure of human nicotinamide phosphoribosyltransferase. J. Am. Chem. Soc. 135, 34853493.

(42) Sun, G., and Nicklaus, M. C. (2007) Natural resonance structures and aromaticity of the nucleobases. Theor. Chem. Acc. 117, 323-332.

(43) Lewandowicz, A., and Schramm, V. L. (2004) Transition state analysis for human and plasmodium falciparum purine nucleoside phosphorylases. Biochemistry 43, 1458-1468.

(44) Kline, P. C., and Schramm, V. L. (1993) Purine nucleoside phosphorylase. Catalytic mechanism and transition-state analysis of the arsenolysis reaction. Biochemistry 32, 13212-13219.

(45) Silva, R. G., Hirschi, J. S., Ghanem, M., Murkin, A. S., and Schramm, V. L. (2011) Arsenate and phosphate as nucleophiles at the transition states of human purine nucleoside phosphorylase. Biochemistry 50, 2701-2709.

(46) sheely, M. L. (1932) Glycerol viscosity tables. Ind. Eng. Chem. 24, 1060-1064.

(47) Karsten, W. E., Lai, C.-J., and Cook, P. F. (1995) Inverse solvent isotope effects in the nad-malic enzyme reaction are the result 
of the viscosity difference between $\mathrm{d} 2 \mathrm{o}$ and $\mathrm{h} 2 \mathrm{o}$ : Implications for solvent isotope effect studies. J. Am. Chem. Soc. 117, 5914-5918.

(48) Lin, Y., West, A. H., and Cook, P. F. (2008) Potassium is an activator of homoisocitrate dehydrogenase from saccharomyces cerevisiae. Biochemistry 47, 10809-10815.

(49) Lin, Y., Volkman, J., Nicholas, K. M., Yamamoto, T., Eguchi, T., Nimmo, S. L., West, A. H., and Cook, P. F. (2008) Chemical mechanism of homoisocitrate dehydrogenase from saccharomyces cerevisiae. Biochemistry 47, 4169-4180.

(50) Goitein, R. K., Chelsky, D., and Parsons, S. M. (1978) Primary $14 \mathrm{c}$ and alpha secondary $3 \mathrm{~h}$ substrate kinetic isotope effects for some phosphoribosyltransferases. J. Biol. Chem. 253, 2963-2971.

(51) Johnson, K. A. (1992) 1 transient-state kinetic analysis of enzyme reaction pathways. In The enzymes (Sigman, D. S., Ed.), pp 1-61, Academic Press.

(52) Johnson, K. A. (1995) Rapid quench kinetic analysis of polymerases, adenosinetriphosphatases, and enzyme intermediates. Methods Enzymol. 249, 38-61.

(53) Hartley, B. S., and Kilby, B. A. (1954) The reaction of pnitrophenyl esters with chymotrypsin and insulin. Biochem. J. 56, 288-297. 